This is an electronic reprint of the original article. This reprint may differ from the original in pagination and typographic detail.

Author(s): Little, Noah; Burger, Birgitta; Croucher, Stephen M.

Title: $\quad$ EDM and Ecstasy : the lived experiences of electronic dance music festival attendees

Year: $\quad 2018$

Version:

Please cite the original version:

Little, N., Burger, B., \& Croucher, S. M. (2018). EDM and Ecstasy : the lived experiences of electronic dance music festival attendees. Journal of New Music Research, 47(1), 78-95. https://doi.org/10.1080/09298215.2017.1358286

All material supplied via JYX is protected by copyright and other intellectual property rights, and duplication or sale of all or part of any of the repository collections is not permitted, except that material may be duplicated by you for your research use or educational purposes in electronic or print form. You must obtain permission for any other use. Electronic or print copies may not be offered, whether for sale or otherwise to anyone who is not an authorised user. 
EDM and Ecstasy: The lives experience of electronic dance music festival attendees.

Noah Little, Birgitta Burger, \& Stephen M Croucher

\section{Author Notes}

Noah Little (MA, University of Jyväskylä, 2016) is a Doctoral Candidate in Psychology in the Department of Psychology, Neuroscience, and Behavior at McMaster University, (noahlittle@hotmail.com)

Birgitta Burger (PhD, University of Jyväskylä, 2013) is a Post-Doctoral researcher in the Music Department at the University of Jyväskylä.

(birgitta.burger@jyu.fi)

Stephen M Croucher (PhD, University of Oklahoma, 2006) is Head of the School of Communication, Journalism and Marketing at Massey University.

(s.croucher@massey.ac.nz)

Please direct all correspondence to Noah Little:

1280 Main Street West, School of the Arts, Togo Solomon Hall Room 424. McMaster University, Hamilton, Canada, L8P 2C8,+1 6475006624 (noahlittle@hotmail.com) 


\title{
EDM and Ecstasy: The lived experiences of electronic dance music festival attendees
}

\begin{abstract}
Attendance at large scale music festivals has captivated a global interest in these spectacular experiences, yet little is known about the lasting benefits and personal changes individuals incur following this event. This study aims to provide a comprehensive exploration of the lived experiences of individuals who attended a multi-day electronic dance music festival. The present study was primarily interested in the perceived beneficial changes within the individual, following their festival experience. We investigated if first time festival attendees perceived changes differed to those of returning individuals. Semi-structured qualitative interviews were used to collect data from 12 individuals who attended the 2015 Electronic Daisy Carnival in Las Vegas. Six participants were first-time attendees while the remaining six were individuals returning to the festival. The data was analysed using Thematic Analysis. Within the data emerged the following central themes: 1) escape, 2) communitas, and 3) self-reported changes; there were 10 subthemes. These findings add to the existing body of music festival literature, further contextualizing how music festivals are both experienced, and reflected upon by individuals. Further, this study highlights the potential lasting changes individuals' experience from attending electronic dance music festivals.
\end{abstract}

Keywords: music festival, electronic dance music, social cohesion, social acceptance, music.

\section{INTRODUCTION}

Music festivals are an important component to regional cultural economies and prospective tourists (St John, 2015). These events are called "festivalscapes" which contain aspects of cultural and social interaction at both local and global levels (Chalcraft \& Maguadda, 2013). The previous decades have witnessed the creation of famous music festivals including Woodstock, England's Glastonbury art and music festival, and Germany's Rock festival, Rock Am Ring. Recently, electronic dance music events are implicated to be the "festivalisation of culture" (Bennett, Taylor, \& Woodward, 2014). These events create an environment that possess unified membership to this experience; wherein patrons transcend the perceived differences among ethnicity, faith and class, and thus exist as a group entity. (St John, 2015).

In the present day, Electronic Daisy Carnival (EDC) is a large music festival hosting 134,000 electronic dance music patrons for three days, in Las Vegas, Nevada, USA (lasvegas.electricdaisycarnival.com). EDC Las Vegas is amongst other electronic dance music festivals experiencing a drastic increase in global mainstream recognition, and record high attendance. To highlight this electronic dance music trend: Tomorrowland music festival in Belgium observed a growth from 50,000 fans in 2008 , to 180,000 in 2013 , and eventually 
400,000 in 2014 (tomorrowland.com). Ultra Miami Music Festival had 100,000 attendees in 2010; this festival has now become a two-weekend show hosting 330,000 people (ultramusicfestival.com).

Previous research suggests individuals attend music festivals for various motives. From a broad perspective, individuals attend special events because of: socialization, family togetherness, event novelty, escape and relaxation, excitement and enjoyment, and cultural exploration (Abreu-Novais \& Arcodia, 2013). As proposed by Dann (1981), individuals are driven to seek out experiences based on push and pull forces. Push factors originate from our internal psychological needs (e.g., socialization) and pull factors from destination specific features (e.g., enjoyable event, novelty). Likewise, Simkova and Holzner (2014) examined the motivation of tourists to attend special events; they reported "seeking personal rewards", "escaping personal environment", and "change form everyday life" as the main motivators to participate in these events.

Specific to music festivals, Faulkner, Fredline, Larson, and Tomljenovic (1999) determined festival visitors were motivated to attend because of: event excitement, novelty, and socialization. Bowens and Daniels (2005) identified three dimensions of motivation for music festival attendees: socialization, music, and overall enjoyment. Additionally, Australian attendees reported the engagement with a festival atmosphere and the participation in diverse activities and workshops at the festival, to be their main attendance motivator (Nicholson \& Pierce, 2001). Further, Gelder and Robinson (2009) compared two UK music festivals motivators. Listening to music or watching an artist was most important at one event, while the atmosphere and opportunities for socialization was the main motivation for attending the other. Lastly, a recent investigation of Chinese music festivals attendees found togetherness, musical enjoyment, and event novelty to be attendance motivators ( $\mathrm{Li} \&$ Wood, 2014). Overall, the motivational themes of music festival attendees gravitate towards socialization, musical enjoyment, and engagement with the festival atmosphere.

Current empirical investigations have determined individuals are attaining benefits from attending these music festivals. First, Packer and Ballantyne (2011) discovered festival participants gained an alternative life outlook and became more open minded. Specifically, they believed the festival allowed opportunities of self-expression and a strengthening of social relationships with those they attended with. Furthermore, 91\% of participants reported 
improved life satisfaction following the music festival, and $89 \%$ believed they grew from the experience. Following their previous investigation, Ballantyne, Ballantyne, and Packer (2013) discovered additional benefits to festival attendance. Namely, improvements in subjective well-being, including feelings of happiness and feeling more positive about life. Also, patrons reported a greater sense of social well-being in terms of social acceptance and social integration. Park (2015) attempted to understand Asian attendees' social acceptance, and cultural belonging within the electronic dance music community. They concluded that Asian American young adults, aged 19-25, are attending electronic music festivals to fulfill a void in cultural acceptance because of their perceived status as foreigner. Lastly, Schäfer, Smukalla, and Oelker (2013) found following intense musical experiences, individuals had felt a strong sense of harmony and wanted to achieve this state once again. In an attempt to relive this harmony, individuals altered their value system, engaged in more meaningful activities, and intensified social relationships (Schäfer, Smukalla, \& Oelker, 2013).

The investigations into the outcomes of these events are becoming ever more necessary because of the primary young adult demographic attending these festivals. Young adults are an extremely malleable population influenced by their surroundings, early experiences, and their social circle. A four-year analysis of EDC medical instances reported the median age of patients to be 22 years of age (Tran et al., 2016). Additionally, the average age of participants was 23 years of age in Park (2015) investigation. Young adults and college aged individuals will be used synonymously hereafter, referring to persons aged 19-25. Given that festivals provide opportunities to establish self-identity, meaning, and social integration, both the behaviours and experiences young adults are subjected to at these immersive festivals can potentially impact them (Packer \& Ballantyne, 2011).

In the current study we wanted to explore the lived experience of individuals attending Electronic Daisy Carnival (EDC), which is among the largest electronic dance music festival in the world (lasvegas.electricdaisycarnival.com). Since the research exploring the lived experience and reflective accounts of festival attendees is sparse, we felt using a qualitative approach would offer the most comprehensive narrative. Additionally, by examining the both new and returning individuals, we aimed to uncover potential similarities or differences among these participants. This includes what is motivating these individuals to continually return or attend for the first time, and what particular similarities or differences in terms of perceived festival experiences they report. Also, we investigated the lasting benefits individuals perceived 
they attained from attending this specific festival because of the known transformative effect of intense musical experiences. Notably, there is a lack of investigations examining immersive electronic music festivals in the existing literature from a retrospective viewpoint. To our knowledge this is the first investigation on electronic music festivals exploring how the experience affected patrons behaviour, thoughts, feelings, thinking and its sustained benefits.

We anticipate this study will contribute to the emerging existing literature on music festival experiences and its impact on attendees' psychological and social well-being. Finally, our participant accounts will aid festival management practices to enact potential changes that can enhance patron experiences. Thus we offer the following research questions.

Research Question 1: What are the reported lived experiences of these intense musical experiences for returning and first time attendees?

Research Question 2: What are the beneficial outcomes experienced by its participants?

Research Question 3: What, if any, are the perceived changes in oneself that are implicated from attending this musical event?

\section{Methodology}

\subsection{Data Collection}

This study used semi-structured in-depth interviews to enable a detailed exploration of participants' music festival experience. This enabled a focused scope of responses from the participants in a semantically rich form, ultimately aiding data analysis. Similar data collection techniques have been applied in other music festival studies when investigating the participant experience in these musical environments (Li \& Wood, 2014; Laing \& Mair, 2015). The aim of the present study was to investigate the perceived festival experience more thoroughly, using questions based on the existing musical literature.

\subsection{Interview Procedure}

Schäfer et al. (2013) kindly shared their interview guide for exploring strong musical experiences that are described as unforgettable and stand out from usual experiences because of its quality. This was translated from 
German using a native speaker. The interview guide was slightly altered to address the aims of this study. The first author carried out interviews with close cooperation with the second author during the summer of 2015 over Skype. All interviews were recorded and transcribed. Appropriate times were mutually agreed upon and coordinated between participant and the researcher for the interview. Examples of questions asked to participants included "How would you describe your emotional state during your time at the festival" and "How did this experience affect or change your behavior or thoughts, thinking, feelings, emotions?". The full interview guide can be seen in Appendix A.

The mean duration for interviews was 24 minutes (range 14-50 minutes). All participants agreed to be audio recorded and were informed their responses would be anonymous; pseudonyms were used to uphold this. Interviews were recorded using Call Recorder (Ecamm, 2015). All interviews were transcribed using F5 Transcription software (NCH Software, 2015).

An advantage of the retrospective method is that approaching an individual during a festival can interrupt their experience. Also, we were interested in the long-term effects which could be narrated upon during this reflection process; especially after sufficient time has passed and internalization of the event has occurred. Additionally, because of the geographic dispersal of the target group, conducting the interviews over Skype allowed the participants to remain in a comfortable and familiar environment, and enabled data collection from various cultures and countries.

\subsection{Participants}

Participants were recruited from two social networking sites, Facebook and Reddit. We recruited 12 individuals, six who attended EDC 2015 for the first time, and six others who were returning to the festival once again. We wanted both newcomers (rookies) and experienced attendees (veterans), allowing contrasts of their experiences to potentially emerge in analysis. Participants were aged 20 to $60(M=27, S D=10.78)$ and predominantly male $(n=10)$. When 12 participants had been interviewed, a point of saturation was achieved (e.g., information from additional interviews largely repeated that of previous interviews) and no more interviewees were recruited (Biddle, Markland, Gilbourne, Chatzisarantis, \& Sparkes, 2001).

\subsection{Thematic Analysis}


The interview data was analyzed using Thematic Analysis, which provides flexibility and pattern identification (Braun \& Clarke, 2006). Thematic Analysis is beneficial when exploring under-researched areas, as is the case in the present study (Braun \& Clarke, 2006). We used an inductive approach for analysis, which allowed codes and themes to develop from the data set itself. Our direction of analysis uses a contextualist method, addressing the ways individuals make sense of their experience, and the broader social context of those meanings. The first author conducted the data analysis. The six-step process by Braun and Clarke (2006) guided our Thematic Analysis. The analysis was carried out with technical assistance of NVivo 11 software (QSR International Pty Ltd, 2015). The process of our analysis was as follows: (1) the first author listened to the interviews and transcribed the recordings (2) after reading through the transcripts several times to familiarize himself, 23 initial codes were found and categorized using Nvivo 11 (3) broader themes were sorted using the previously generated codes and discussed with the second author to establish meaning (4) further refinement led to defining and naming 10 subthemes emerging under three broadly defined themes and the creation of a thematic mapping (5) revisiting of the chosen themes and subthemes were discussed with the second and third author to further establish clarity and ensure it fit the overall narrative (6) examples of quotes were chosen to illustrate the aspects of the festival experience.

\subsection{Ethical Considerations}

The University of Jyväskylä ethical guidelines for human subjects were strictly abided by. All participants were sent a study information sheet prior to study commencement and all names are pseudonyms.

\section{Findings}

When analyzing participants' experiences of their Electronic Daisy Festival encounter we found the following three themes to be of central importance: (a) the opportunity to escape, (b) communitas, and (c) self-reported changes. Among these themes are various sub-themes that address the research questions concerning the lived experience of this specific music festival. 


\subsection{Theme 1: Opportunity to escape}

The theme "Opportunity to escape" describes the removal from ones' mundane lifestyle while attending EDC. We present three subthemes from the data in Figure 1. First, the psychological escape one achieves from everyday life stressors and responsibilities, such as employment or school. Second, the physical removal from everyday environment by means of travelling to the festival location. Third, the retreat from societal norms and pressures, which is removed at EDC.

\subsubsection{Psychological Escape}

First, the chance to escape from everyday life was present across the whole data set. Participants stated EDC was an opportunity to escape from the world, a temporary way to forget their worries, obligations, and present life circumstances.

\footnotetext{
"It's almost like, they give you a place to escape to, especially in Vegas, but with insomniac events, especially in EDC, it's like, you feel like it's a place to escape to, you know everyone has their issues and so does everyone else, but you're going there. I want to say it's almost like you're in heaven, fuck everything else, everything is going on the back burner, I'm going to enjoy myself for these three days" (Brad, Rookie).
}

EDC provides its patrons an opportunity to psychologically escape from their daily troubles and responsibilities. The participants were engulfed in the music festival experience and experienced temporary relief from their present life. This offers insight into why individuals are keen to pursue this psychological break, similar to a vacation. It offers a pause from the struggles of daily life which can become overwhelming for people. Thus, this event offers an escape from their thoughts or worries stemming from their life.

\subsubsection{Physical Escape}

The next theme that originated from the data was escape from one's physical environment. IsoAhola's (1982) motivation theory suggests humans are driven by the desire to fulfil intrinsic rewards and the desire to escape their everyday environment. Given that all attendees must travel to the event site, some locally, others internationally, the act of travelling was another means of escape that participants commented on. This travel experience enabled removal from 
the perceived monotony of everyday life. The exposure to new experiences including new cuisine, novelty events, and different cultures are likely to occur while in travel.

"EDC is not just the event, it's literally, you're in Vegas you're going to have a good time in Vegas. So people show up before the event, it's also a really hype place, like shit happens in Vegas, because you're going somewhere you're not used to. Like for me, I want to get turnt and get crazy in Vegas" (Blake, Veteran)

Importantly, Las Vegas, where EDC is held, is a world-renowned festive destination with endless entertainment including large-scale nightclubs, 24-hour casinos, and fine dining eateries. Therefore, individuals attending EDC will have access to an array of activities, atop of their EDC event; leading to more opportunities of leisure, fun, and potentially greater overall enjoyment. According to Leask (2014), Generation Y individuals, persons born between 1982 and 2002, are frequent travelers, spend considerable amounts of money on travel, and desire new experiences to a greater degree in comparison to other generations. Except for one participant, all the interviewees were among this generation. Additionally, Jennings, Cater, Lee, Ollenburg, Ayling, and Lunny (2010) noted Generation Y individuals are willing to pay above average rates for a guaranteed memorable experience, for instance, music performances, and remote holiday vacations. Thus, this demographic pattern observed supports the literature as to why the majority of individuals who attend these events are among the young adult age range whom are likely seeking out these unforgettable experiences.

\subsubsection{Societal Escape}

The final theme of escape is the empowerment of EDC to offer its attendees to deviate from social norms and expectations. Participants reported the feeling of not being judged by others and having no fear of being their true selves while at EDC. This included behaving and dressing in attire that is typically seen as out of place or unacceptable in most societies. Individuals at EDC frequently commented on the diverse tolerance of individuals. It appears people are unconcerned with how others are dressing or acting, with a seemingly widespread level of respect and acceptance. However, returning individuals are familiar to the irregular dress styles and behaviours often associated with attendees at electronic dance music festivals. Interestingly, individuals who were new to EDC seem to adopt the understanding that there is no judgment, and people can be who they are; it is a safe space, where all are welcome. These reports emulate findings by Li and Wood (2014) who reported patrons of an Asian electronic 
dance festival (MIDI festival) were motivated to attend because of the opportunity for spiritual escape. Spiritual escape is removing oneself from the societal constraints and the yearning for a freer environment. Whilst the participants in the present study are mainly from western countries, as opposed to China, a more authoritarian country, there is still an expected degree of decorum among their home societies.

\footnotetext{
"But who am I to judge, EDC is supposed to be a place where you express yourself. If you want to show up in a pair of boots and a fuzzy hat, I don't understand it, but hey go for it. Like you're here to be yourself and to you know, fit in the way that you feel the way that you can, and if that's the way you feel that you fit in then by all means go for it" (Katy, Veteran)

"Everybody just has good vibes, there's no hate, you can be gay, lesbian it doesn't matter whoever you are were still going to love you. I think it's the culture, like nobody judges you, everyone is there to be themselves" (Andy, Rookie)
}

\section{Theme Summary}

Festival attendees provided accounts of acceptance and an opportunity for free self-expression in this environment. The lack of judgement, and social restrictions at the festival environment led to feelings of general acceptance among others; without the fear of being socially rejected. These narrations depict how this specific music environment promotes social belonging, regardless of one's own personality, sexual preferences, or dress attire. This tolerant behavior consequently creates a relaxed atmosphere of individuals who experience the temporary removal of socially conceived expectations, and negative discriminatory behaviors. In agreement with previous music festival investigation (Abreu-Novais \& Arcodia, 2013), participants noted being able to escape from their responsibilities and everyday routines was a strong motivator to attend, and their temporary vacation from society was met with stress relief and relaxation. The occurrence of this escape theme depicts the ideas of Iso-Ahola's (1982) innate desire for humans to escape their everyday environment and the desire to achieve a change from everyday life (Simkova \& Holzner, 2014). Further, participants particularly enjoyed being able to be whom they wanted, without the fear of being judged by others. Additionally, these narrations portray a distaste of a highly judgmental society existing outside the music festival environment. These conformity stressors may be a daily cause of concern for individuals, and consequently adds to the desire of attending this kind of festival to escape these societal constraints.

\subsection{Theme 2: Communitas}


This theme will discuss the type of interactions experienced at the music festival: Peace, Love, Unity, Respect (PLUR), the role of music on groups, and positive social interaction. The theme title "Commnitas" was coined by Victor Turner (1969), which describes the deep feelings of community expressed by our participants at EDC. Turner (1969) described festivals as spontaneous communitas; group gatherings that possess the ability to unite strangers, remove social inequalities such as class or ethnicity, and are outside the constraints of typical society. This is strikingly similar to what occurs at Electronic Daisy Carnival. As defined by Stone (2008) these musical gatherings possess "an intense community spirit, resulting from a shared experience associated with an atmosphere of social equality, sharing, intimacy and togetherness" (p. 215). Participants reported EDC contained an intense sense of unity, and all participants upheld mutual respect for each other, with a strong desire to interact. This second theme, illustrated in Figure 2, contains three subthemes: Peace, Love, Unity, Respect (PLUR), Positive Social Interactions, and Role of Music.

\subsubsection{PLUR}

A frequent topic discussed by the participants was the ideals of Peace, Love, Unity, and Respect (PLUR) at the festival. Frankie Bones, a UK DJ during the 1990's, is credited with enacting and ultimately shaping present day ideals of PLUR. When producing his massive warehouse parties, he wanted to ensure a conflict-free environment where everyone could enjoy the music. In a recent article, Bones stated, "Everything else changed, but the ideals of PLUR have remained true. It's about looking out for people, and if somebody was in trouble, you helped them out" (Insomniac, 2016). The ethos of PLUR attempts to pursue an environment of harmony or a far-fetched utopia among festival-goers. Participants had various anecdotes and opinions on the topic of PLUR.

\footnotetext{
"No matter race, no matter from where you're from, social standing, everyone has that common I guess denominator or core value. Where we all can respect each other, we can right off the bat start talking to each other. Like, there's no preconceived ideas about the other person and you can automatically relate to them like you've known this guy, you feel like you've known them forever, this understanding, of each other" (Danny, Rookie)
}

The interviewees descriptions appear to reveal a sense of genuine respect and appreciation for their fellow man. Their adoption of the PLUR values while at this event had led them to a specific type of interaction and behaviour that is expected or perhaps organically occurring at 
EDC. There is some amount of encouragement from the event organizers to behave in this manner. As stated in an interview, the EDC organizer and creator said

"The concept of P.L.U.R held people together then. In a very REAL way. It still holds the same gravity for me now. I'm not sure when it became popular or "Cool" to clown on "PLURRRRR Bro". But I just laugh and give those people a Big Hug, because they don't get it. PLUR is O.G...PLUR is why I keep doing Events, and The spirit of PLUR saved my Life a few times when things got sticky back in the Day", (Ward, 2015)

Additionally, the social conformity effect of enacting the ways of PLUR is reinforced in this musical environment as new attendees will follow the lead of returning and experienced fans familiar with the expected decorum. To achieve social harmony, individuals must have a mutual sense of what is important in life, or personal values (Coombs, 1966; Edwards and Cable, 2009). This is viewed as more important than having reciprocal traits. Individuals with similar musical preferences perceive others of the same musical preferences to share similar personal values to themselves (Boer et al., 2011). In addition, individuals commented on how they felt this type of behaviour and interaction was unlike anything they have experienced in comparison to other music festivals.

"If you bump into someone at say a metal concert, it's all "fuck you buddy" and you push the guy. If you bump into some at EDC, "ah man, so sorry, where are you from" all of a sudden it starts a conversation, it's kind of mind blowing" (Jake, Veteran)

The discrepancy between different musical environments and their respective patron behaviors are of specific interest as this depicts an expectation of unique decorum at these events.

\subsubsection{Positive Social Interaction}

Another theme discussed by all participants was the enjoyable social interactions incurred while at the festival. Abreu-Novais and Arcodia (2013) noted the socialization aspect of music festivals to be the most compelling motivational factor for attending these events. Throughout the interviews, participants constantly exclaimed the joy of being with others, family members, and meeting new people.

"When you walk in there, it's almost as if, everybody's mentality changes and everybody's super kind and umm, willing to get to know you, and willing to help you out" (Katy, Veteran) 
"Everyone says hi to each other, waves at each other, it's like as if you all knew each other, but in reality like no one really does, but it doesn't even matter. People will randomly feel open and come talk to you about different things about what your wearing or where you're from, so like it's really cool" (Becca, Veteran)

These positive social interactions appear to be fueled by the PLUR mentality present at EDC. Whilst the PLUR ethos may contribute to these social connections, even without PLUR, these interactions would likely still occur, though, perhaps the level of authenticity and frequency may not be as explicit compared to other music events. Our data supports previous research by Gelder and Robinson (2009) who reported the atmosphere and opportunities for socialization as the main motivation for individuals attending Glastonbury Music Festival. Lastly, this type of group behaviour is extremely uncommon in most present day societies. Being able to easily interact with countless strangers, who are enthusiastically engaging with you, is almost unheard of. We would argue this sense of social understanding, bonding, and enjoyment from these interactions at EDC is due to innate human social behaviours being fulfilled. This has been described as the human tribal inclination.

The tribal instinct hypothesis asserts an evolutionary adaptation occurred to handle difficult situations faced by early humans including mating, food gathering, safety and security (Stürmer $\&$ Snyder, 2009). While at EDC, for a limited amount of time, you are part of a group, or tribe, as we will hereafter synonymously refer to it. At the festival, you have to determine who is friend or foe, how will you ensure resources (i.e., water, food), and can you trust others around you. Further, being in a new environment can be difficult, and banding together as one can ensure the sense of security and belonging. Also, being part of a group leads to various psychological benefits because of the typical behaviours that take place within a group. For example, individuals will commit helping acts to others within the group (Van Vugt, Snyder, Tyler, \& Biel, 2000), as was observed heavily at EDC.

\footnotetext{
"So we would meet people that were tripping way, way out of control. So I would grab onto their shoulder to make sure they were okay. We all had Camelbacks ${ }^{1}$, me and my buddy the first time, and the second time also we had it, and we find these people and were like hey man what's wrong and they say they haven't drunk water in forever, and then we're like "hey man, have some of this" so they're drinking your water and they start to calm down a bit, it makes you feel really good that you helped these people" (Jake, Veteran)
}

Even if temporary, it appears that individuals at EDC experience this tribal connection and attained a deep sense of pleasure from it. Strangers at this event became banded together and were concerned for the general well-fare

\footnotetext{
${ }^{1}$ A Camelback is a wearable water carrying pouch typically in the form of a backpack.
} 
of others. Their temporary tribe.

\subsubsection{Role of Music}

The majority of the participants stated the importance of music while at the festival. They attended their favourite DJ sets and were able to explore their preferred musical genre, and discover new artists. Notably, there were often emotional and social connections with music depicted throughout their experience.

\footnotetext{
"Me personally, my favourite genre is trance, like I love me some trance, for me trance is an emotional genre, you connect to, so when your connecting to the music and everybody is connecting to it, then your gonna connect to other people." (Gary, Rookie)
}

Notably, participants report being engrossed in the music and experiencing a sense of connection with the other attendees. Importantly, an abundance of literature has determined music to facilitate pro-social behaviour (Bakagiannis \& Tarrant, 2006) and can create a sense of group identity among individuals (Laiho, 2004). Additionally, individuals who share musical preferences have more positive evaluations of each other (Lonsdale \& North, 2009; North \& Hargreaves, 1999). Thus, given the role of social facilitation by music, the positive evaluation of others with similar musical taste, and the bonding potential of music, it is fathomable individuals will have a strong sense of community and social cohesiveness at EDC. Thus, the pro-social behaviours observed at the festival and the positive interactions exerted from individuals will further contribute to the enjoyable festival experience.

Finally, numerous participants reported an intense emotional experience while at EDC that had a musical origin with a personal connection.

\footnotetext{
"My father passed away in umm, May of 2014. And so actually, Above and Beyond played a tribute to fathers, on Father's Day during their set and if you have the time to go watch it, I would go watch it. I started to cry in the middle of the stage, it was like crazy, that was definitely a highlight. I can't even say it in words, it was just like a magical experience" (Katy, Veteran)
}

\footnotetext{
"You see other people crying to the same song you are, even though, they have different experiences for crying. You turn to them and your like, what the fuck are you crying about? And they say it's that song. So like, they had a more, emotional connection. Maybe it's someone passing away, or things like that and you coped with it with the song and, I feel like when you see it live, you can see the emotional connection, because I finally saw the DJ that produced it, and I don't feel alone. Because if that dude is
} 
crying over there, and like, even though you don't feel the bond, I'm not the only one going through this." (Blake, Veteran)

These intense bodily responses to the musical experience are of particular interest. According to Gabrielsson (1991) and Waterman (1996), crying is an emotional response that can be caused by music. These intense emotional responses from attendees display the intimate connection with the music and it was this moment that became a memorable moment to them. From an evolutionary function, crying is believed to signal others the need for help, and can create social bonds with others (Bekker \& Vingerhoets, 2001; Zeifman, 2001). However, little research has explored the role of crying for joy. Frey (1985) suggested crying out of happiness is due to a pre-existing worry, and the crying is the relief from this (Lund, 1930). Overall, the emotional response illustrates the impact of music on these individual's lives, and the personal connection that exists with these festivals.

\section{Theme Summary}

PLUR as a festival theme has been loosely covered in recent investigations, such as in Park (2015) and St John (2015). This harmony, defined as the feeling of being one with oneself and the world (Schäfer et al., 2013), was verbalized in our participants in the form of intense unity, belonging, and community. Based on participant descriptions, we believe PLUR is a novel social code of behaviour that temporarily fulfills fundamental human needs, and is perhaps an awakening and connection to the human core. As described by Schäfer et al. (2013), following an intense musical experience (IME), the sense of harmony stemmed from listener's sense of freedom, clarity, inner balance, and deep relaxation. In our study, the festival atmosphere engulfed by PLUR, and its philosophy influenced attendees to these outcomes.

Additionally, music being a social facilitator and creating a commonality among attendees was exclaimed in our study, and echoes the findings of previous investigations (Boer et al., 2011). Boer also found an individual's musical preference is associated with their values (2009). As such, Boer et al. (2011) proposed a model where shared musical preference creates the idea that others sharing this music listening experience possess the same values, consequently leading to enhanced social attraction. Our participants, who display an interest in electronic dance music, a genre associated with extroversive personality traits (Rentfrow \& Gosling, 2003), could contribute to the high incidence of social interaction and positive appraisal of fellow attendees. This is because an extroverted individual is likely to engage in social activities, and be more open to new experiences. Their personalities alone may contribute the incidence of interaction among attendees. 
Next, movement synchrony with others can promote feelings of social connectedness (Cirelli, Wan, \& Trainor, 2016). During the festival, dancing and clapping to the music with others occur spontaneously between performers and attendees alike; strengthening these social behaviours bonds among strangers. Also, group vocalizations (i.e., chanting, singing) foster social bonds as it is a group directed goal that all members share and unanimously understand (Einarsdottir \& Gudmundsdottir, 2015). Thus, a massive group of electronic music patrons singing a familiar song as a collective will lead to these communal feelings and this group chant furthers their welcoming mentality towards each other and enhances these bonds. It is postulated that singing removes the need for personal interaction and that large groups can bond using songs to unify strangers (Pearce, Launay, Dunbar, 2015). As a whole, these instances of assisting others depict the general caring attitude of fellow attendees, reiterates the PLUR ethos of the festival, and the social bonding behavior of individuals at these events is intensive. The tribal instinct theory will be revisited at the conclusion.

\subsection{Theme 3: Self-reported Changes}

In this theme, we discuss the retrospective narrative aspects of the music festival: how the participants reflected on their experience, what changes they perceived after the event, and the changes in value systems. A primary goal of this investigation was to explore the beneficial outcomes of attending EDC. Maslow claimed individuals could attain peak experiences by using music. As defined by Leach (1962) a peak experience is

\footnotetext{
"that highly valued experience which is characterized by such intensity of perception, depth of feeling, or sense of profound significance as to cause it to stand out, in the subject's mind, in more or less permanent contrast to the experiences that surround it in time and space" (p.11).
}

Maslow $(1962,1964,1968)$ believed peak experiences could add meaning to our life, and alter how we view our own lives. Importantly, peak experiences are thought to be associated to achieving self-actualization (Maslow, 1954). As previously mentioned, self-actualization is the highest level of Maslow's hierarchy. This is when the individual realizes their potential and is associated with deep emotional experiences, and time disassociation (Maslow, 1962; Maslow, 1971). In regard to music, Gabrielsson and Lindström (1995) proposed strong experiences with music (SEM) possess the potential to alleviate grief and provide consolation, overcome temporary depression, provide feelings of openness and freedom, and allow insight into alternative lifestyle behaviours. Recently, Schäfer et al. (2013) investigated intense musical experiences and found following this experience, individuals had the desire to adopt new values, and strengthen or create social relationships. In figure 3, aspects of the reported changes 
by Schäfer et al. (2013) were paralleled in the present study with participants exclaiming their adoption of new values, specifically those of PLUR, a restored belief in humanity, experiencing intense euphoria, and having spiritual experiences.

\title{
3.3.1 Adoption of PLUR Values
}

Following their immersion in this festival atmosphere, it appeared the individuals had taken up new values, following their exposure. The first subtheme, the adoption of PLUR values, was a common statement from individuals when they reflected on their music festival experience.

\footnotetext{
"Well the PLUR lifestyle kind of stuck to me. I'm more like, just nice to everybody. I'm not like hating on people anymore. I just try to know them and then judge by their character, if that's how they are that's how they are. I don't tell them off or anything like that" (Andy, Rookie)
}

\begin{abstract}
"It's more of a lifestyle than anything, it's a way of life and I have taken it to heart big time. I've always been a really relaxed and cool person, but you know, I've had my issues where I've gotten frustrated and been an asshole. Especially after EDC and looking back on it, these issues don't really matter. I mean it's like, why sweat the small stuff, so you kind of take the experience from EDC in Vegas and you apply it to the rest of your life, you let it influence you in a positive way, because if you forget about it all when you go home what's the point. I mean I feel like I'm a different person now" (Brad, Rookie)
\end{abstract}

The data suggests individuals are motivated to uphold this type of conduct in their lives because of the enjoyment and harmonistic outcomes when implementing this type of behaviour and value system at EDC. Hypothetically, the EDC event may contain unique significance and importance if the individual is willing to challenge or change ones outlook on life and their current value system. As defined by Schwartz (1994, p. 20) "A value is a belief pertaining to desirable end states or modes of conduct, that transcends specific situations, guides selection or evaluation of behaviour, people, and events, and is ordered by importance relative to other values to form a system of value priorities". What is contained in the essence of EDC that is causing these positive changes? As noted by Schäfer et al. (2013) "the establishment of new values requires people to reject social norms"(pp.539), this was frequently observed at EDC. He continues, "people leave their former self-image behind and create a new one that comes from their inner self, this process of disengagement" (pp.539); being at a music festival in our case, "enables them to recognize and establish their real values and goals" (pp. 539). EDC might therefore provide individuals an opportunity to step back from their normal lives, and 
typical social constraints. Thus, leading to a reassessment of oneself on how they conduct their behaviour in day-to-day life. An individual exclaimed this re-appraisal.

\begin{abstract}
"Step back and reset mentality is umm, step back and look at the things that you do, that your used to doing, don't even think about it, and reset your mentality. Just like trying to be, trying to smile at everybody that you see, like you would do at EDC, everybody you see you high five, you smile at them, you say just good things to them and the real world, people don't do that. You walk by somebody on the street or whatever and you don't even look at them or acknowledge them or anything like that. So changing your mentality like just smiling at somebody can, can make their day, and it might even help you" (Gary, Rookie)
\end{abstract}

\title{
3.3.2 Altered Faith in Humanity
}

The second subtheme within the theme "self-reported changes" was the restored faith in humanity and a greater respect for their fellow man. The observed behaviour and positive interaction was exclaimed by many during EDC and was seemingly held onto and changed the outlook on life by our participants following the festival.

"When I left for like the next month, I was almost re-energized. You know what I mean, my faith in humanity had kind of been restored...it's going to sound pretty fucking stupid but, I do feel like I have tried to be a better person, after seeing people being nice to each other. It's kind of weird I know (Jake, Veteran)

This restored faith in humanity, and improved respect for individuals is seemingly a result of the observed behaviour and interactions at EDC. Once again, it appears individuals gained an alternative view on life following their enjoyable experience; and aspects of these positive interactions led to these changed outlooks.

\subsubsection{Mystical Like Experience}

The next subtheme is the resemblance of a mystical like experiences and the inexplicability of attending EDC. William James (1902) defined a mystical experience as being:

1. Ineffable or too great for words.

2. Noetic in which they achieve a revelation (noetic: Greek word meaning inner wisdom).

3. Transient or temporary states lasting short duration. 
4. Passive, which means the individual cannot control the experience but is rather part of it.

Individuals were continually unable to describe their experience adequately, a term called ineffability. Also, they appeared to reach certain realities and understanding of the gravity of their situation, and how they were a part of something greater than themselves. Furthermore, others drew parallels between EDC and a religious experience.

"Honestly it's not even, you can't even explain how it feels because you have to like, be there to experience it" (Becca, Veteran)

\begin{abstract}
“It's also a religious experience, I'm not like very religious whatsoever, but you know how people go to church or to get rid of their worries, to not think about anything else it's just, they're in the moment, going to the concert was kind of like that where, there was nothing else in my mind just being there you know, enjoying the atmosphere begin with other people, the same way, it's just you know, I have a lot of friends that are religious and that's exactly how they describe going to church or a congregation, so to me it's like they go for that, this is how I felt at the festival" (Danny, Rookie)
\end{abstract}

The descriptors of the EDC event, and participants' inability to depict their experience displays its magnitude and overwhelming nature to the individual. Mystical like experiences can have sustained and substantial personal meaning as well as spiritual significance (Griffiths, Richards, Johnson, McCann, \& Jesse, 2008), are arguably present in these music festival experiences. These intense experiences with music at EDC may be an event that cause lasting changes in an individual's life; as mystical experience are known to cause sustained impacts on people's lives. Thus potentially, individuals who engage in these intense musical experiences are having mystical experiences that may lead to lasting potential benefits in their lives.

\title{
3.3.4 Significant Life Experience
}

This subtheme of reported changes was the narration of this event being a significant life experience in the individual's life. Notably, when comparing the significance appraisal of rookies and veterans, a few differences emerge. When asked, "would you consider this a significant life experience", it was the rookies more than the returning veterans, who were adamant about their festival attendance being a significant life event. Some of our rookie participants believed this festival to be in their top five most significant experiences in their lives, while others believed it was among the top three. For instance, individuals compared this experience to be as significant as being told they are loved by an intimate partner. Others 
participants stated that what they experienced at this festival was vastly different from previously attended music festivals.

"Top 3 experiences in my life, for sure, EDC is probably my best experience, that even comes close, maybe the closest feeling is when my ex-girlfriend told me she loved me but, she's my ex" (Brad, Rookie)

"I notice a big difference between EDC and Veld and Osheaga. Everybody is one, everybody is united at EDC and I didn't even get the same feeling at Veld or any other festival that I have been to" (Katy, Veteran)

The descriptions by our participants depicts this experience as a monumental, and selfimportant event in their lives. Thus, providing additional insight and support that these experiences possess potential of lasting impact on its attendees; as they believe it to be among their most significant life event.

It was an entirely new experience for them, although this unfamiliarity does not explain its perceived life significance. Comparatively, some veterans did concur EDC was a significant life event, though this was not always the case. However, it is likely that because of their previous experiences with EDC, it did not have such a blatant impact on veterans, as they have already been exposed to the EDC festival experience. Importantly, these reports depict how this festival is viewed as a significant life event to festival attendees. Thus, it is plausible that the experience of EDC is an overwhelmingly positive and enjoyable experience that carries personal meaning and significance. This is an interesting finding, as this short festival experience of only three days can have such a large impact on individuals.

\footnotetext{
"you're only there for two or three days but, they say memories last a lifetime and all the memories you made, the people that you meet, you don't get that every day, even if it's just three very very short days, you know, you meet a lot of people, make a lot of great memories you experience a lot of things that you wouldn't otherwise experience and in the scene that you absolutely love, I don't know man, it's just, I don't know it's just one of those things that you have to experience" (Gary, Rookie)
}

Finally, another common way individuals attempt to achieve significant and meaningful experiences are through religious practices. Various scholars have noted the benefits of an individual's involvement with religious practices including greater coping strategies, positive emotions, and healthier lifestyle (Seybold, \& Hill, 2001). Additionally, a meta-analysis by Koening and Larson (2001) found a positive relationship among individuals with religious beliefs and their reported life satisfaction. Large musical gatherings share similarities of religious ones. For example, the members typically adhere to specific dress styles; there is a 
communal understanding of expected behavioural practices, a sense of unity, and being socially involved in an accepting environment.

\section{Theme Summary}

Our participants' narration of their adoption of PLUR value systems in their own lives support the notion that this specific event in their lives had a lasting impact on themselves. Also our participants experience with the PLUR decorum echoes previous literature, specifically Park (2015) and St John (2015). Additionally, these outcomes support previous work wherein individuals were motivated to alter their behavior and their value systems; following an intense musical experience (Schäefer, 2013). The intense musical experience reporting from the data replicates the characteristics of a mystical experience. Notably, mystical experiences can create long term changes in individuals' personality (Griffiths et al. 2008) and outlook on life (Cakic, Potkonyak \& Marshall, 2010). Patrons of EDC noted retrospective changes in their personality, including an increased willingness to be kind to others, and improved faith in humanity. Also, as noted by festival attendees, they believed EDC was an extremely significant life event, with undertones of spirituality. Therefore, this significant life event of attending EDC can be monumental in a person's life and may influence their wellbeing and outlook with spirituality.

\subsection{Rookies and Veterans Comparisons}

Our initial intention to recruit rookie and veteran festival attendees revealed small differences to their reported experiences. Both the rookie and veteran patrons reported the intense musical experience of their EDC encounter. Of note, this novel event that occurs annually was observed by both groups to incite excitement, motivation to attend, and an intense social atmosphere. Our first time attendees believed this was an experience that will be a fond memory; that this event led themselves down a journey of music festival experience, dance music, and the positive PLUR behavior.

\footnotetext{
"It's just something that I will never forget, it was my first time and just, this is how I came into the EDM culture and I learned about PLUR and Candy and gloving, and other things, this was my stepping stone, you get what I mean" (Vince, Rookie)

"You go there and your just, your mind, is, your mind just explodes, the moment you walk into EDC, and you see everyone, just little black dots, and your like wow is this really happening, like to me I walk in, I see it the music turns on, i'm like I'm ready to rage, ready to dance" (Andy, Rookie)
} 
The first time attendees were overwhelmed in their experience when faced with their ability to escape, PLUR mentality by other patrons, and the opportunities to engage with the activities at EDC. Their novel excitement was likely shared by veterans during their first time attendance but they have grown accustomed to the experience. Veteran individuals who were returning to the music festival reported excitement in their anticipation to return to the event, and nostalgia. Though it was not as prevalent nor as overwhelming as the initial experience to that of their Rookie counterpart.

\footnotetext{
"The first time is more like, people tell you about it and so you kind of know what to expect, but like you, you have to experience it for the first time and like it's now the third time, I still get super excited because you know what's there, but it's still a surprise" (Becca, Veteran)
}

The first time individuals did seem to adopt the PLUR mentality more intensely and take in the EDC experience fondly, this is partly expected due to the unfamiliarity of the festival itself. Also, at the time of the interview, first time attendees may still be processing and integrating their significant experience into their life. This may explain their greater exclaimed excitement and fondness of EDC, compared to the returning veterans. Thus, the initial exposure is likely the most memorable and transformative, even if new experiences emerge in subsequent instances. The differing experiences between first time attendees and returning individuals at a festival have a wealth of research. First time attendees have a greater amount of variation in expectation among their perceived image of their experience, to that of repeat visitors. This first timers experience is based upon external experiences (i.e., family, friends, videos, photos); comparatively veterans form their image based on previous actual experiences (Fakeye \& Crompton, 1991). Our first time participants likely possessed different experience expectations when entering their first EDC experience, compared to our Veterans whom have already had this experience. Thus potentially creating different motivations to attend, festival experience, and perceived benefits between the two groups. Furthermore, first time visitors travel further (Kruger, Saayman, \& Ellis, 2010), and are more likely to seek variety and new cultural experiences; compared to the relaxation and social seeking veterans (Gitelson \& Crompton 1984; Hughes \& Morrison-Saunders 2002). Consequently, the new attendees were motivated to engage in these new experiences that the festival had to offer (i.e., rides, artwork, large stages); creating an enhanced experience for themselves. Compared to that of a veteran who has already experienced these activities, they are still experiencing an enjoyable festival, but the novelty and excitement is undoubtedly lower than a first time attendee who is enthralled by this intense musical experience. Thus we posit that first timers were motivated to attend 
because of prospective enjoyable activities, and their own perceived image of the EDC experience. Though our Veterans had already experienced the event and were poised to return because of their previous positive experience.

\section{Discussion}

\section{The lived experienced of festival attendees}

The narrative themes presented here depicted the 12 experiences of individuals attending EDC in June 2015. People reported attending the festival because it allowed them to escape from their everyday environment, forget their life responsibilities, and remove themselves from undesired societal pressures. Additionally, attendees discussed the strong sense of community that created an environment for positive social interaction, a unique harmonistic setting with other patrons, and a place for musical enjoyment and experience. Further, participants exclaimed their desire to adopt new and altruistic behaviuors after continuously witnessing this positive conduct at EDC. Also, individuals believed their EDC experience to be of personal significance to themselves, and can be compared to a mystical or religious experience. Overall, the experience of EDC appears to psychologically appease individuals, especially in social domains (i.e., social interaction, social. acceptance, shared musical experience). Thus, we believe this festival experience and the activities and interactions within, can be beneficial to attendees well-being and social health.

To summarize, the results of this study indicate how individuals attending music festivals are attaining various benefits and are viewing their experience as a significant event that has transferable effect into daily life. The majority of music festival investigations have focused on drug incidence (Dilkes-Frayne, 2015), and social inclusion (Park, 2015). This study is among others (Ballantne, Ballantyne, \& Packer, 2013; St John, 2015), exploring the benefits individuals are attaining from attending these electronic musical events. The aim of the present study was to understand the lived experiences of an individual attending Electronic Daisy Carnival, and to address the existing gaps in the present literature on music festival experiences. Namely the perceived lasting changes on one's life following a festival, the differences between first timers and returning attendees experiences, and the spiritual and mystical 
attributes of this event. Following the festival, it appears individuals have a desire to adopt new values, gain an altered outlook on life, and are less stressed.

This research demonstrates how the ethos of PLUR is a governance of expected behaviour while at EDC. The PLUR philosophy appeared as the driving force of the positive energy felt by attendees, and may play a major role in contributing to the intensely positive social interactions. Therefore, if its patrons view EDC as a religious like experience, or a significant event, these similar beneficial outcomes (i.e., greater mental health, changed outlook on life, behavioural modification) may be associated with attending these types of musical events. The lasting effects and changes participants attributed to their EDC festival experience surprised us. The adopting of PLUR values showed how impactful these observed behaviours at the festival were to the individual, and the resulting desire to incorporate it into their own lives. This behavior could be explained by modelling (i.e., social conformity to PLUR ideals and actions) was transferred outside the festival environment and corresponds to previous investigations. Instances wherein participants believed these lasting effects presented themselves appeared in the form of feeling more confident, and wanting to be a better person. Thus, this study depicted the potentially positive social benefits of attending these events, and also its possible long term and lasting effects individuals attain from these personally significant positive experiences. As previously mentioned, Schäfer (2013) noted following an intense musical experience (IME), people were motivated to improve harmony within their own lives including their social relationships and values. Next, the claims of wanting to improve oneself, and the increased faith in humanity was also intriguing and was echoed by our participants.

"When I left for like the next month, I was almost re-energized. You know what I mean, my faith in humanity had kind of been restored. That people could be nice to each other on such a large scale" (Jake, Veteran)

Additionally, parallel to previous work, Ballantyne, Ballantyne, and Packer (2013) noted attending a festival for multiple days, compared to only one day, led to a stronger and more positive experience for attendees. Thus, a stronger impression was formed, likely because of the extended duration of festival atmosphere exposure. Our EDC patrons experienced a threeday immersive musical experience. Attendees are able to enjoy an adult playground full of carnival rides, engage with creative artists and their works on display, and enjoy a spectrum of large scale electronic music stages with top Disc Jockey's from around the world. The festival attendees in the present study were present for each day and reported being at the festival for 
12 hours each day. This lengthy immersion, range of activities that an individual can participate in, and the overall positive atmosphere of patrons likely contributed to the enjoyment of the festival and contributes to the overall memorable experience. EDC is not only a musical event, but an amusement park, an art gallery, and a musical space for all to enjoy. This type of environment and its attendee's decorum is a contrast to not only other musical genres but also to other electronic music festivals; as supported by our participants' narrations.

\footnotetext{
"I notice a big difference between EDC and Veld and Osheaga. Everybody is one, everybody is united at EDC and I didn't even get the same feeling at Veld or any other festival that I have been to" (Katy, Veteran)

"I come from a more rock and metal type background, and as I got older it kind of stopped. I was kind of expecting, I mean you meet a couple dicks anywhere you go. I didn't meet anyone hostile, everyone was super friendly, you know" (Jake, Veteran)
}

Interestingly, electronic dance music is a genre associated with extroversive personality traits (Rentfrow \& Gosling, 2003). Thus, these individuals who are extroverted are talkative and energetic and it is these factors creating a large group of socially strong people at the EDC festival. Also, the mutually agreed upon ethos of PLUR that is present at the festival contributes to the positive experience of individuals, and the welcoming nature of the people.

As previously stated, intense mystical experiences can have lasting influences on induvial following a specific experience, in this instance an intense music festival experience. The inability for individuals to describe their feelings when discussing the entirety of their EDC experience, and the similarity between their experience and that of mystical like event is a momentous outcome. Griffiths et al. (2008) used psilocybin, a powerful hallucinogenic to achieve these mystical experience in his subjects, which produced long term changes in personality, specifically openness. Also, Dimethyltryptamine (DMT), an endogenous hallucinogen has also shown to produce meaningful experiences by its users and positively alter their outlook on life (Cakic, Potkonyak, \& Marshall, 2010). If EDC is eliciting a mystical experience for its attendees, this is a particularly notable discovery; to achieve this state and to enact personal changes as a result of a musical experience.

It should be noted that electronic music events are often associated with drug use by its patrons (Kavanaugh \& Anderson, 2008; Johnson, Voas, Miller, \& Holder, 2009). Only three participants reporting consuming illegal substances, namely Ecstasy. Ecstasy is a synthetic drug that has a mix of stimulatory and hallucinogenic effects and enhances serotonin release 
(MacLean, Johnson, \& Griffiths, 2011). Ecstasy causes elevated cortisol levels that lead to an increased feeling of energy and a lack of fatigue (Parrott, 2012). Individuals taking these substances are likely aware of the qualities possessed by it and during a dance music event, ecstasy can be an enjoyable substance that can delay fatigue and increase euphoria; potentially explaining its widespread use at these events. Comparatively, the remaining participants prided themselves on being sober at the event and were uninterested in illegal substances while at the festival. Legal substances consumption included alcohol, energy drinks, and tobacco. Participants potentially decided not to partake in consumption of substances because of the risks associated with these behaviours including ingesting unverified substances, physiological risks, and illegality. However, exploring the issue of substances was not the aim of the study and therefore cannot be addressed.

\section{Implications}

This study provides the first comprehensive investigation of the lived experiences of music festival attendees at Electronic Daisy Carnival by examining both first time attendees, and returning ones. The research successfully supported previous scholarly work (Packer, \& Ballantyne, 2010; Ballantyne, Ballantyne, \& Packer, 2013) depicting music festivals to be a socially enhancing environment that could contribute to one's social-wellbeing and other benefits for its attendees (i.e., escape, relaxation, adventure). We believe these events are potentially a method to maintaining social health; as the festival acts as a social entity allowing the individual to easily identify with others through music; and exists as a social outlet; consequently, fulfilling intrinsic human needs (i.e., social acceptance, belonging, love) as outlined by Maslow (1954). Further, this work illustrates the spiritual significance and personal meaningfulness attached to these musical experiences, as narrated by our participants. Also, the exploration of first time attendees and returning visitors further the knowledge of motivators, and different experiential outcomes perceived by these two distinct groups. Lastly of significance, the festival and its behavioural code of PLUR appears to be commonly internalized and acted out, throughout the festival, but also following it. Interestingly, PLUR, which possess attributes of altruism (i.e., helping others) and positive social decorum (i.e., harmony, respect, acceptance), is a behaviour that sporadically initiates once the festival begins, and after seeing and experiencing its benefits, individuals adopt this behaviour and mindset into their own lives. 
As previously mentioned, the tribal instinct hypothesis proposes a human adaptation occurred to overcome the difficulties faced by our ancient ancestors such as food gathering, ensuring of safety and security, and enhancing offspring survival (Stürmer \& Snyder, 2009). Humans are meant to live among others, we are social creatures; "it is commitment to a group and the set of norms that bind it together" Kelly, 2014. p.518). However, modern humans have become widely individualistic (Grossmann and Varnum, 2015) and have reduced feelings of sympathy for others (Konrath, O’Brien, \& Hsing, 2010). Importantly, our participants felt they were part of something greater than themselves with a strong sense of unity. Participants believed EDC was an openhearted environment, granting belonging to "outsiders", those who had difficulty fitting into society, or who were often rejected by peers. Social integration, as defined by Keyes (1998), is the extent people feel a shared commonality with the individuals in their immediate surrounding. Additionally, Maslow (1954) put forth in his hierarchy the need for humans to feel a sense of belonging and acceptance. Thus, given this intense sense of unity and belonging, and using PLUR as a positive ethos value system, a strong group mentality is formed at EDC for young adult individuals; potentially leading to psychological benefit to these social integration behaviours.

The large young adult population whom make up the EDC attendees comprise of demographic (Generation Y) hold the lowest affiliation with religion, poorest attendance records for places of worship, and view religious organization negatively (PEW, 2010; PEW, 2014). The pursuit of spirituality is indisputably present, and is innate human nature (Maslow, 1971), the authors believe there could be a need to fulfill a spiritual vacancy in this demographic group. Notably, the desire for individuals to seek spirituality by means of group rituals, such as religious gatherings are ever-present (Miller \& Thoresen, 2003). Emulating an intense social situation to that of among a group of welcoming strangers, for instance a Church; the music festival provides a similar environment of trust and acceptance. Importantly, individuals who undertake spiritual behaviours are identified to have greater physical and psychological health measures, for example lower rates of depression and anxiety (Sperry, 2001; Koenig, McCullough, \& Larson, 2001). Thus, potentially attending EDC is a method people are using to attain a spiritual experience and consequently enhance their psychological and social health by fulfilling this innate human desire.

To conclude, we have chosen a passage that we believe summarizes the EDC experience exquisitely. 
"I think, the vibe of the people in general, made it like, forget the amazing music, the amazing visuals, the huge production, it was the people that made it memorable man, just everyone being nice to each other, you know what I mean, having some respect for each other. It was really bizarre at first, but when I look back at it, it makes sense, because they are trying to live out that PLUR lifestyle, and I think that's what totally made it, the people." (Jake, Veteran)

\section{Limitations and Future Directions}

This article has several limitations and future directions. First, it is limited by the relatively small number of participants interviewed, and the primarily young adult demographic recruited. Future investigations should involve a greater number of participants from various age groups, not primarily young adults, college-aged individuals. These different age groups may display different motivational factors and lasting musical experience outcomes by the individuals. For instance, adults may not be motivated to seek social acceptance or identity formation to the intensity of their youth counterpart. Potentially, an older demographic are interested in engaging in the musical experience and obtaining a novel experience; rather than achieving feelings of social belonging.

Another limitation of this study was that no interviews took place before the event, which may have provided insight into the anticipation, expectations, and previous knowledge about the event. However, interviews taken prior to the event may have influenced participant's expectations, and only rookie reporting's could be taken, since veterans would have prior experience with the festival. Future studies could interview first time attendees (rookies), which may provide a more inexperienced account compared to returning festival patrons. The rookies could discuss their experience of anticipation about this enormous event, what they enjoyed the most; in a pre and post interview. However, it should be said that being able to compare first timers and veterans was helpful during analysis.

Next, because the interviews were conducted between two and three months following the festival, some details of the experience could have been forgotten or overlooked due to passage of time. However, we believe our time frame allowed for individuals to reflect upon their experience and to determine how it impacted their lives as they returned to day to day living. Individuals may not be able to accurately assess a lasting impact shortly after the experience as they could still be on an emotionally elevated mindset following this intense musical experience. Future investigations could administer several instances of various measurements on attendees. Participants would be reassessed at short term seven days and two months, 
followed by long term 14 months. The various testing times would determine potential longterm sustained effects within the individual after their music festival experience.

Importantly, further research is required to compare the lived experiences and the reported subjective changes from different festival locations. If comparing festival experiences in different countries, (i.e., Brazil, Belgium, South Korea) we could gain a better understanding on the impact of music festivals on individuals from different parts of the world. It is possible these reported changes in our population could be observed in other places as well, or perhaps their outcomes would be different from ours.

Finally, potential limitation in this study was the bias of self-selection. Given that the topic was disclosed to potential participants in the recruitment process, self-selection may have resulted from individuals wanting to share their experience, and discouraged those who did not want to discuss their experience; thus the respondents may not be fully representative of the population. Also, the respondents did not voice negative experiences of EDC and future investigations could explore undesirable outcomes from a festival experience including illegal drug usage, heat exhaustion, and financial cost.

\section{Conclusion}

Electronic Daisy Carnival provides individuals an opportunity to escape from one's everyday routines, surroundings, and societal pressures. The temporary festival environment fueled by the PLUR code of behaviour fulfills primitive human needs including intensely positive and accepting social interactions, attaining a source of spirituality and, and feelings of unity. From this enjoyable experience, attendees are implementing positive changes to their value systems, behaviour, and are viewing life more optimistically. These favorable changes may be a result of attending EDC, and could prove beneficial for long-term psychological and social wellbeing. Lastly, these intense musical experiences that possess positive outcomes may be a contributing factor as to why festival attendances are achieving record high numbers and are responding to an increased global demand for shows by creating new ones each year.

\section{Funding}


The authors declare no conflict of interest, nor, did we receive any financial support for the undertaking of the present study. 


\section{References}

Abreu-Novais, M., \& Arcodia, C. (2013). Music festival motivators for attendance: Developing an agenda for research. International Journal of Event Management Research, 8(1), 3448.

Alvarado, A .(2015). It's a \$6.2 billion industry. But how did Electronic Dance Music get so popular? Retrieved from http://edition.cnn.com/2014/12/18/world/how-did-edm-get-sopopular/

Amsterdam Dance Event. (2015). Drug Warning ADE. Retrieved from http://www.iamsterdam.com/en/visiting/whats-on/monthly-eventcalendar/october/amsterdam-dance-event/drug-warning

Armstrong, S. (2008). An Echo of Delphi: The Python Games Ancient and Modern. Rosicrucian Digest 2, pp 52. Retrieved from. https://1df116ccf7e76f4fadc6db61b658f2565d5f24ddeaaa20b9f7d5.ssl.cf5.rackcdn.com/w_12_Echo_Delphi.PDF

Bakagiannis, S., \& Tarrant, M. (2006). Can music bring people together? Effects of shared musical preference on intergroup bias in adolescence. Scandinavian Journal of Psychology, 47(2), 129-136.

Ballantyne, J., Ballantyne, R., \& Packer, J. (2013). Designing and managing music festival experiences to enhance attendees' psychological and social benefits. Musicae Scientiae, $18(1), 65-83$.

Bekker, M. H. J., \& Vingerhoets, A. J. J. M. (2001). Male and female tears: Swallowing versus shedding?. In A. J. J. M. Vingerhoets, \& R. R. Cornelius (Eds.), Adult crying. A biopsychosocial approach. (pp. 91-114). Hove (UK): Brunner-Routledge.

Bennett, A., Taylor, J., \& Woodward, I. (2014) The festivaliztion of culture (Eds). Aldershot (UK) Ashgat

Biddle, S. J., Markland, D., Gilbourne, D., Chatzisarantis, N. L., \& Sparkes, A. C. (2001). Research methods in sport and exercise psychology: Quantitative and qualitative issues. Journal of sports sciences, 19(10), 777-809.

Boer, D., Fischer, R., Strack, M., Bond, M. H., Lo, E., \& Lam, J. (2011). How shared preferences in music create bonds between people: Values as the missing link. Personality and Social Psychology Bulletin.

Boer, D. (2009). Music makes the people come together: Social functions of music listening for young people across cultures. Unpublished Thesis

Book, R. (2014). Electronic Daisy Carnival and 400,000 Attendees contribute 322 Million to Las Vegas Economy. Retrieved from http://www.musictimes.com/articles/7279/20140703/electric-daisy-carnival-400000-attendees-contribute-322-million-las.htm 
Bowen, H., \& Daniels, M. (2005). Does the music matter? Motivations for attending a music festival. Event Management, 9(3), 155-164

Braun, V., \& Clarke, V. (2006). Using thematic analysis in psychology. Qualitative research in Psychology, 3(2), 77-101.

Cakic, V., Potkonyak, J., \& Marshall, A. (2010). Dimethyltryptamine (DMT): Subjective effects and patterns of use among Australian recreational users. Drug and Alcohol Dependence, 111(1), 30-37.

Coombs, R. H. (1966). Value consensus and partner satisfaction among dating couples. Journal of Marriage and the Family, 28, 166-173.

Csikszentmihalyi, M. (1990). Flow: The psychology of optimal performance. NY: Cambridge University Press.

Dann, G. M. S. (1981). Tourist motivation: An appraisal. Annals of Tourism Research, 8(2), 187-219.

Duff, C. (2005). Party drugs and party people: Examining the 'normalization'of recreational drug use in Melbourne, Australia. International journal of drug policy, 16(3), 161-170.

Dilkes-Frayne, E. (2015). Drugs at the campsite: Socio-spatial relations and drug use at music festivals. International Journal of Drug Policy.

Edwards, J. R., \& Cable, D. M. (2009). The value of value congruence. Journal of Applied Psychology, 94(3), 654-677.

Einarsdottir, S. L., \& Gudmundsdottir, H. R. (2015). The role of choral singing in the lives of amateur choral singers in Iceland. Music Education Research, 3808,1-18.

Fakeye, P. C., \& Crompton, J. L. (1991). Image differences between prospective, first-time, and repeat visitors to the Lower Rio Grande Valley. Journal of travel research, 30(2), 10-16.

Faulkner, B., Fredline, E., Larson, M., \& Tomljenovic, R. (1999). A marketing analysis of Sweden's storsjoyran music festival. Tourism Analysis, 4(3), 157-171.

Forsyth, A.J.M, Barnard, M, \& McKeganey, N.P (1997). Musical preference as an indicator of adolescent drug use. Addiction 92(10), 1317-1325.

Gabrielsson, A. (1991). Experiencing music. Canadian Music Educator, Research Edition, 33, 21-6.

Gabrielsson, A., \& Lindström, S. (1995). Can strong experiences of music have therapeutic implications? In R. Steinberg (Ed.), Music and the mind machine (pp. 195-202). Berlin, Germany: Springer.

Gelder, G., \& Robinson, P. (2009). A critical comparative study of visitor motivations for attending music festivals: A case study of Glastonbury and V Festival. Event Management, 13(3), 181-196.

Gitelson, R. J., \& Crompton, J. L. (1984). Insights into the repeat vacation phenomenon. Annals of tourism Research, 11(2), 199-217. 
Griffiths, R. R., Johnson, M. W., Richards, W. A., Richards, B. D., McCann, U., . . Jesse, R. (2011). Psilocybin occasioned mystical-type experiences: immediate and persisting doserelated effects. Psychopharmacology, 218(4), 649-665.

Grossmann, I., \& Varnum, M. E. (2015). Social structure, infectious diseases, disasters, secularism, and cultural change in America. Psychological science, 26(3), 311-324

Hudson, S., Roth, M. S., Madden, T. J., \& Hudson, R. (2015). The effects of social media on emotions, brand relationship quality, and word of mouth: An empirical study of music festival attendees. Tourism Management, 47, 68-76.

Hughes, M., \& Morrison-Saunders, A. (2002). Impact of trail-side interpretive signs on visitor knowledge. Journal of Ecotourism, 1(2-3), 122-132.

Iso-Ahola, S. E. (1982). Toward a social psychological theory of tourism motivation: A rejoinder. Annuals of Tourism Research, 9, 256-62.

James, William. "Mysticism" from Lectures XVI \& XVII of The Varieties of Religious Experience: A Study in Human Nature (1902).

Jennings, G., Cater, C., Lee, Y. S., Ollenburg, C., Ayling, A., \& Lunny, B. (2010). 6 Generation Y: Perspectives of Quality. Tourism and Generation Y, 58.

Johnson, M. B., Voas, R. A., Miller, B. A., \& Holder, H. D. (2009). Predicting drug use at electronic music dance events: self-reports and biological measurement. Evaluation review, 33(3), 211-225.

Kavanaugh, P. R., \& Anderson, T. L. (2008). Solidarity and drug use in the electronic dance music scene. The Sociological Quarterly, 49(1), 181-208.

Kelly, D. (2013). 'Moral Disgust and The Tribal Instincts Hypothesis,' Cooperation and Its Evolution, Eds. K. Sterelny, R. Joyce, Calcott, B, \& B. Fraser. Cambridge, MA: The MIT Press, pp. 503-524.

Keyes, C. L. M. (1998). Social well-being. Social Psychology Quarterly, 61, 121-140.

Koenig, H. G. and D. B. Larson. 2001. Religion and mental health: Evidence for an association. International Review of Psychiatry 13(2), 67-78.

Koenig, H. G., McCullough, M. E., \& Larson, D. B. (2001). Handbook of religion and health. New York: Oxford University Press.

Konrath, S. H., O'Brien, E. H., \& Hsing, C. (2010). Changes in dispositional empathy in American college students over time: A meta-analysis. Personality and Social Psychology Review.

Kruger, M., Saayman, M., \& Ellis, S. M. (2010). Does loyalty pay? First-time versus repeat visitors at a national arts festival. Southern African Business Review, 14(1), 79-104.

Laiho, S. (2004). The psychological functions of music in adolescence. Nordic Journal of music therapy, 13(1), 47-63.

Laing, J., \& Mair, J. (2015). Music festivals and social inclusion. The festival organizers' perspective. Leisure Sciences, 37(3), 252-268.

http://lasvegas.electricdaisycarnival.com/ : Retrieved Attendance Figures 
Leach, D. (1962). Meaning and correlates of peak experience (Unpublished doctoral dissertation). University of Florida, Gainsville.

Li, Y.-N., \& Wood, E. H. (2014). Music festival motivation in China: free the mind. Leisure Studies, 1-20.

Lim, M. S., Hellard, M. E., Aitken, C. K., \& Hocking, J. S. (2007). Sexual-risk behaviour, selfperceived risk and knowledge of sexually transmissible infections among young Australians attending a music festival. Sexual health,4(1), 51-56.

Lund, F. H. (1930). Why do we weep?. The Journal of Social Psychology,1(1), 136-151.

MacLean, K. A., Johnson, M. W., \& Griffiths, R. R. (2011). Mystical experiences occasioned by the hallucinogen psilocybin lead to increases in the personality domain of openness. Journal of Psychopharmacology, 25(11), 1453-1461.

Chalcraft, J., \& Magaudda, P. (2013) "“Space is the Place": The Global Localities of the Sònar and WOMAD Music Festivals". In Festivals and the Cultural Public Sphere, eds. Gerard Delanty, Liana Giorgi and Monica Sassatelli, 173-189. New York: Routledge.

Maslow, A .(1954). Motivation and personality. New York, NY: Harper. p. 236.ISBN 0-06041987-3

Maslow, A. H. (1962). Lessons from peak experiences. Journal of Humanistic Psychology, 2, 9-18.

Maslow, A.H. (1964). Religions, values, and peak-experiences. Columbus: Ohio State University Press.

Maslow, A. H. (1968). Toward a psychology of being (2nd ed). Oxford, UK: D. Van Nostrand

Maslow, A.H. (1971). The farther reaches of human nature. New York, NY: Arkana/Penguin Books.

McKay, H (2014) Dangerous dance music EDM concerts plagued by security health issues. Retrieved from. http:/www.foxnews.com/entertainment/2014/07/02/dangerous-dancemusic-edm-concerts-plagued-by-security-health-issues/

Miller, W. R., \& Thoresen, C. E. (2003). Spirituality, religion, and health: An emerging research field. American psychologist, 58(1), 24.

Nicholson, R., \& Pearce, D. G. (2001). Why do people attend events? A comparative analysis of visitor motivations at four south island events. Journal of Travel Research, 39(4), 449460.

Pahnke, W. N. (1963). Drugs and mysticism: an analysis of the relationship between psychedelic drugs and the mystical consciousness. Unpublished doctoral thesis. Boston: Harvard University.

Packer, J., \& Ballantyne, J. (2010). The impact of music festival attendance on young people's psychological and social well-being. Psychology of Music, 39(2), 164-181.

Park, J. S. (2015). Searching for a Cultural Home: Asian American Youth in the EDM Festival Scene. Dancecult: Journal of Electronic Dance Music Culture, 7(1), 15-34.

Parrott, A. C. (2012). MDMA and 5-HT neurotoxicity: the empirical evidence for its adverse effects in humansno need for translation. British journal of pharmacology, 166(5), 1518-1520. 
Pearce, E., Launay, J., \& Dunbar, R. I. (2015). The ice-breaker effect: singing mediates fast social bonding. Royal Society open science, 2(10), 150221.

Pedersen, W., \& Skrondal, A. (1999). Ecstasy and new patterns of drug use: a normal population study. Addiction, 94(11), 1695-1706.

PEW Research Center (2010). Religion Among the Millenials. Retrieved from. http://www.pewforum.org/2010/02/17/religion-among-the-millennials/

PEW Research Center (2015). Millenials views of new media, religious organization grow more negative. Retrieved from. http://www.pewresearch.org/facttank/2016/01/04/millennials-views-of-news-media-religious-organizations-grow-morenegativel

Privette, G., \& Brundrick, C. M. (1991). Peak experience, peak performance, and flow: Correspondence of personal descriptions and theoretical constructs. Journal of Social Behavior and Personality, 6(5), 169.

Rentfrow, P. J., \& Gosling, S. D. (2003). The do re mi's of everyday life: the structure and personality correlates of music preferences. Journal of personality and social psychology, 84(6), 1236.

Robertson, H . (2015). Top 10 EDM and Dance Festivals in the USA. Retrieved from https://www.festicket.com/magazine/top-10-edm-and-dance-festivals-usa-2016/.

Schäfer, T., Smukalla, M., \& Oelker, S. (2013). How music changes our lives: A qualitative study of the long-term effects of intense musical experiences. Psychology of Music, $42(4), 525-544$.

Schwartz, S. H. (1994). Are there universal aspects in the structure and contents of human values? Journal of Social Issues, 50(4), 19-45.

Seybold, K. S. and P. C. Hill. (2001). The role of religion and spirituality in mental and physical health. Current Directions in Psychological Science 10(1), 21-24.

Šimková, E., \& Holzner, J. (2014). Motivation of Tourism Participants. Procedia-Social and Behavioral Sciences, 159, 660-664.

Sperry, L. (2001). Spirituality in clinical practice: Incorporating the spiritual dimension in psychotherapy and counselling. Philadelphia: Taylor and Francis

Sterling, S. (2016). Frankie Bones on the Origins of PLUR. Insomniac. Retrieved from https://www.insomniac.com/media/frankie-bones-origins-plur

St John, G. (2015). Introduction to Weekend Societies: EDM Festivals and EventCultures. Dancecult: Journal of Electronic Dance Music Culture, 7(1), 1-14.

Stone, C. (2008). The British pop music festival phenomenon. In J. Ali-Knight, M. Robertson, A. Fyall, \& A.Ladkin(Eds.), International perspectives of festivals and events: Paradigms of analysis (pp. 205-224). London, England: Elsevier.

Stürmer, S., \& Snyder, M. (2009). The Psychological Study of Group Processes and Intergroup Relations in Prosocial Behavior. The psychology of prosocial behaviour: Group processes, intergroup relations, and helping, 3. 
http://www.Tomorrowland.com : Retrieved: Attendance figures

Tonedeaf (2016) Six dead, countless overdoses: Why has Australia's music festival culture turned deadly? Retrieved from. http://www.tonedeaf.com.au/466572/are-the-recentdeaths-at-aussie-music-festivals-a-cultural-problem.htm

Tran, A., Zitek, T., Reyes, R., Forred, W., Carlo, P., \& Carrison, D. (2016). 91 An Analysis of Four Years of Experience at the Electric Daisy Carnival in Las Vegas. Annals of Emergency Medicine, 68(4), S37.

Trichter, S., Klimo, J., \& Krippner, S. (2009). Changes in spirituality among ayahuasca ceremony novice participants. Journal of Psychoactive Drugs, 41(2), 121-134.

Turner, Victor. 1969. The Ritual Process: Structure and Anti-Structure. Chicago: Aldine.

http://www.Ultramusicfestival.com: Retrieved: Attendance figures and new festival locations

Van Vugt, M., Snyder, M., Tyler, T. R., \& Biel, A. (2000). Cooperation in modern society. Promoting the welfare of communities, states and organizations: Routledge.

Waterman, M. (1996). Emotional responses to music: Implicit and explicit effects in listeners and performers. Psychology of Music, 24(1), 53-67

Ward, N. (2015). Pasquale Rotella Defines The True Meaning Of 'PLUR' | Your EDM. Retrieved August 26, 2016, from http://www.youredm.com/2015/07/14/pasqualerotella-defines-the-true-meaning-of-plur/

Zeifman, D. M. (2001). An ethological analysis of human infant crying: Answering Tinbergen's four questions. Developmental psychobiology, 39(4), 265-285. 


\section{Appendix A}

Adapted Schafer Interview Guide (Translated from German)

\section{$\underline{\text { 1. General Information }}$}

Name

Location

Age

Music Interest

\section{Interview Introduction}

1. "I want to know about your festival experience"

"During the interview I will take notes as you speak, think aloud don't filter what comes to your mind. Everything is important, there isn't anything that is too small or unimportant. You can take your time and have a break if you wish, this is not a race. Do you have any questions, are you clear of how the interview will go?"

\section{Priming}

1. Please think about the festival situation, and tell me when it was?

2. Where was it?

3. If there were special surroundings or atmosphere, what was the context?

4. Match the intensity with other activities or events?

5. How does it compare to the other events of intensity (sports, amusement park, walking in park)?

\section{Deeper Questions}

1. Now we are going to dive into different emotions and thoughts that you had at that point during the festival experience?

2. How would you describe your emotional state during your time at the festival?

3.How do you think it effected your festival experience?

4. Please describe a specific memory you had on the individuals at the festival?

5. What did you take out of the experience, what did you take out of it for yourself?

6. How did this experience affect or change your behavior or thoughts, thinking, feelings, emotions?

\section{Effect on Others}

4.3. How can what you experienced, impact others, or is it transferable onto others?

1. How can this affect others around you?

2. How did you feel in the interview?

\section{Experience Causing Changes}

1. How can I imagine it, please explain the festival scene to. How could one imagine it?

2. Why do you think there are such specific experiences or memories, why do these things happen what is causing them or it?

3. In your opinion what is the value of attending a festival?

4. When this experience did not lead to a change or difference in yourself, why do you think this was or why did this happen?

5. What do you think that such, or such experiences can be used in your daily life? 
6. How often have you had these intense music experiences?

$1-5$ times, $5-10$, more than 10

7. Do you use your experiences to get to your goals/achieve your goals?

Do you use these experiences to achieve something, or get to the next level?

8 . Would you say for yourself that you grew though this experience or situation?

\section{Interviewer post follow up notes}

\section{Interview Reflection}

After the interview took place you can look at it afterwards

1. What was noticeable or disturbing, or unique, something that it is special. Something that is noticeable

2. Describe the person, how did she look, describe her body language, what were they like

3. What did I think about during the interview, what did I perceive

4. Additional stuff

5. How did the interview itself go, good bad

6. Others, additional things 